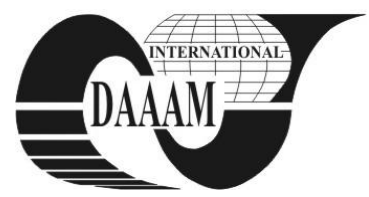

\title{
CONTROLING AND MONITORING SYSTEM FOR THE PRODUCTION OF BIODIESEL
}

\author{
PLSEK, S[tanislav]
}

\begin{abstract}
Method of biodiesel production process and it's monitoring is solved in this article. Controlling and monitoring system is realized on base of knowledge of the free fatty acids transesterification to the biodiesel. Programmable logic controller is used with a setting of two - position controller with penalization including the identification of step response on real device. Monitoring is solved locally on the connected touch panel or remotely via web server and web browser.

Key words: biodiesel, free fatty acids, PLC, control, visualization
\end{abstract}

\section{INTRODUCTION}

Biodiesel is currently used as an alternativefuel with all it's advantages and disadvantages. Advantages includes production from renewable resources and the low environmental burden and lower $\mathrm{CO}_{2}$ emissions the using regular diesel. Disadvantages include higher cost of production and higher emissions of nitrogen oxides.

Production is using transesterification of free fatty acids. It's solved (Ataya et al., 2006; Canakci \& Gerpen, 2001; Van Gerpen, 2005) and it's dealt with our university.

Because process was controlled manually and it was time consuming, I designed a simple system for transesterification using programmable logic controller and two - position controller with penalization. This was adjusted after identification on step response on real device.

The result is easy to control the process using the LCD touch panel, or remotely using web browser or sending SMS messages.

In the future it would be appropriate to extend the automatic control of the entire biodiesel production process from leather residues milling to final purification of biodiesel.

\section{TRANSESTERIFICATION}

Production of biodiesel through a chemical reaction transesterification with presence of these materials:

- Free fatty acids - fats from the remains of leather from the leather industry or used cooking oil from food-processing industry.

- Methanol.

- Acid or alkaline catalyst, according to the used raw materials, usually dissolved in methanol.

Methyl esters - biodiesel and glycerin are creating by this reaction. Glycerin can be easily removed from the biodiesel, because it is indissoluble in methyl esters and it has higher density. For these reasons, it can be removed in a centrifuge.

In the 70th-80th years was proposed using vegetable oil as alternative fuel, but was found to be unusable of it's high viscosity. However this deficiency is removed by transesterification.

During the development several studies were present in which different parameters of reaction were changed. It was found that the speed of reaction is strongly dependent on temperature: at $32^{\circ} \mathrm{C}$ reaction time takes 4 hours, but at $60^{\circ} \mathrm{C}$ reaction time takes only 1 hour. Also tests were conducted without catalyst, but it was necessary to reach a temperature $300^{\circ} \mathrm{C}-350^{\circ} \mathrm{C}$ and molar ratio $42: 1$ of methanol to oil.

Potassium hydroxide or sulfuric acid in the presence of methanol is usually used on place of catalyst. But it content of unsaturated free fatty acids in the fats.

If we want to achieve maximum yield in the production, we must strictly observe ratios of individual substances, temperature and reaction time.

\section{TECHNICAL EQUIPMENT}

PCD2.M5540 Saia programmable logic controller was chosen, because it's durability and built-in web server is used (Hardware PCD2.M5xxx, 2009). To control speed of singlephase asynchronous motor of agitator was selected Invertek OptiDrive E2-1Ph frequency changer. This changer has the option of using external signal or built-in buttons on body of the device to control it, but you can use only one of them.

As the thermometers in reactor were chosen two pieces of Pt1000 thermometer. One of them is located in a sensor pocket in the main reactor area. The second is placed near the heater, because we need protect the oil from local over heating.

Semiconductor relay is used to control the electrical heating element, which allows the use of PWM modulation, while does not destroy contacts as mechanical relays. It also reduces electromagnetic interference, since the relay switches at zero voltage.

To control of equipment was selected touch-screen LCD panel, type PCD7.D410, and G10/CM100 GSM modem sending and receiving SMS, because of the possibility of remote control.

Pt1000 thermometers and analog outputs for drive frequency changer are connected by using PCD2.W525 analog module (Hardware manual PCD2.W525, PCD3.W525, 2007). Digital inputs and outputs are connected through with other I/O modules.

\section{CONTROLLER STRUCTURE DESIGN}

\subsection{Step response identification}

To identify the step response was chosen step form $4 \%$ to $6 \%$ of heating power. Maximal power value of identification was limited by $6 \%$ to prevent overheating. Several measurements were performed and static and dynamic characteristic was calculated from these measurements. The results were averaged. The static characteristic (1) shows that system is linear, the step response show that system is aperiodic of second order.

$$
y=7,3 x+32,3
$$

$$
G(s)=\frac{8,808}{12185,3 s+1}
$$




\subsection{Determination of the controler}

To control the temperature of the reaction mixture was chosen two - position controller with penalization.

Practically it is a two-position controller, but due to the modification used an action variable is penalized around the set point value. Calculation of penalty (Balate, 2003; Vasek, 1994) is given in the following equation (3):

$$
\begin{gathered}
k_{p}=1+\left(1-\frac{w-y}{y} \cdot \frac{1}{\frac{p_{p}}{2}}\right) \cdot\left(k_{p_{\max }}-1\right) \\
k_{p_{\max }}=\frac{u_{\max }}{u_{s t \check{r}}}
\end{gathered}
$$

Several simulations were performed and the best value of $k_{p_{\max }}$ was selected, because $k_{p_{\max }}$ can be adjusted form 0.8 to 1.2 times of the calculated value. Measurements were taken for this $k_{p_{\max }}$ on real device. As shown in Fig. 1., controlled variable reaches the set point value without overshoot in time up to 4 minutes. Also you can see penalized action variable when the regulated temperature reach $54^{\circ} \mathrm{C}$ in Fig. 1. This measurement was carried out for $p_{p}=20 \%$.

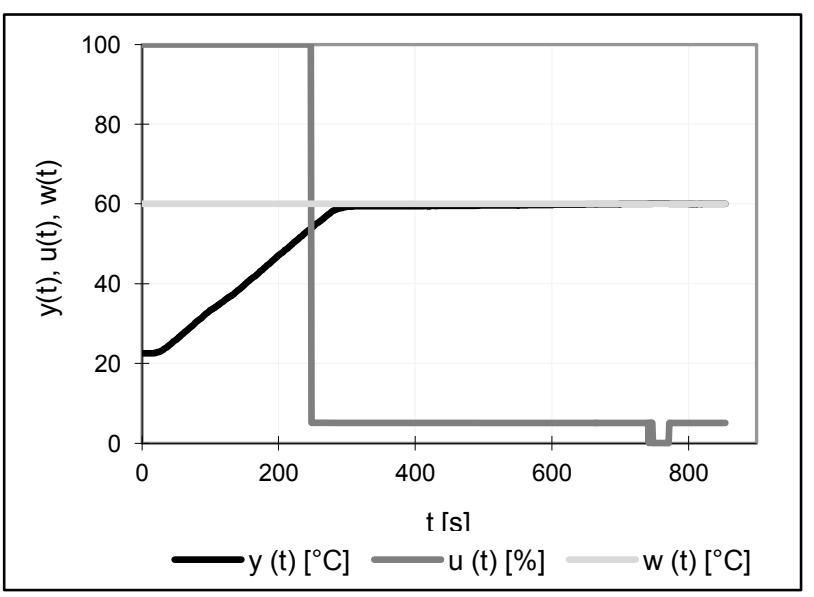

Fig. 1. Verify of the proper setting of the controller on real device

\section{PROCES VISUALIZATION}

Built-in web server in programmable logic controller was used to visualize the process. Visualization pages can be displayed on the LCD touch screen or computer after connect by UTP cable.

Device can be controlled in manual mode when you can control all the elements belonging to a reactor individually. When using an automatic mode after running the program, you can only monitoring the state of variables or shut down equipment in emergency state.

In automatic mode, the device can be controlled using of SMS messages. They can set the parameters of chemical reaction, such as time or temperature and they can be sent to our chosen mobile phone number with information about actual state or eventual failure.

SMS messages control using DTMF commands (Plsek, 2011). The following line shows an example of an SMS message:

\section{$\# 1 \# 500 * 0 * 1 * 1 * 1 * 2 * 1 \# 600 * 0 * 100 * 1 * 200 * 3 * 600 * 4 * 500 \#$}

where individual elements have the following meanings:

- \# is used to separate the DTMF commands

- $*$ is used to separate individual parameters within a DTMF command
According to the above properties we can expand the message to the following parts:

- \#1 - activates DTMF server, sent SMS must always it contain

- \#500 - used to set binary values, where each number is followed by the output logical value, command $\# 500 * 0 * 1 * 1 * 0$ mean that output 0 has log. 1 , output 1 has $\log .0$, etc.

- $\# 600$ - used to set the integer parameters to output, syntax correspond to previous command, then the $\# 600 * 0 * 100 * 1 * 200 * 3 * 600$ sets output 0 to value 100 , output 1 to value 200 , etc

- \# - the last character terminates the DTMF command

To faciliate control you can use a shortened vision of commands with a description of the command, and these messages can be saved in memory of a mobile phone.

\section{CONCLUSION}

Monitoring and controlling system has been created based on the technological requirements of the biodiesel production. Production efficiency is increased and time is saved, if this created system is used. Due to the requirements for temperature control, the two-position controller with penalization was used with two precision thermometers. In spite of it's simplicity controlled variable hasn't overshoot. Given the reaction characteristic was necessary to control the mixer speed. For this purpose frequency changer was connected to existing singlephase motor.

We used LCD touch panel connected to PLC for ease of controlling system. Also we used built-in web server for remote control with computer and GSM modem for control via SMS messages.

In the future it would be appropriate to extend the automatic controlling system to other elements of biodiesel production, such as purification biodiesel, methanol removal or preparation of used raw materials.

\section{REFERENCES}

Ataya, F.; A. Dube, M.; Ternan, M. (2006). Single - Phase and Two - Phase Base - Catalyzed Transesterification of Canola Oil to Fatty Acid Methyl Esters at Ambient Conditions. In Ontario, Canada, p. 5411-5417. Ind. Eng. Chem. Res. Department of Chemical Enginering, Centre for Catalysis Research and Innovation, University of Ottawa, Ontario

Balate, J. (2003). Automatics Control, BEN - technicka literatura, ISBN 80-7300-020-2, Praha

Canakci, M.; Van Gerpen, J. (2001). A Pilot Plant to Produce Biodiesel from high free Fatty Acid Feedstocks. In Paper No. 016049 at the 2001 ASAE Annual International Meeting Sacramento Convention Center. Sacramento

Hardware PCD2.M5xxx. 26/856. (2009). Saia - Burgess Electronics. 229 p. Available from: http://sbc-support.ch/ Accessed: 2011-09-29

Hardware manual PCD2.W525, PCD3.W525. 26/853. (2007). Saia - Burgess Electronics, 9 p. Available from: http://sbcsupport.ch/ Accessed: 2011-09-29

Plsek, S. (2011). Controling and monitoring system for laboratory equipment for the production of biodiesel, Diploma thesis, Tomas Bata Univerzity in Zlin, Zlin

Van Gerpen, J. (2005). Biodiesel processing and production. In Fuel Processing technology 86. University Of Idaho, USA. p. $1097-1107$

Vasek, V. (1994) Microcomputer Monitoring and Controling Systems, Habilitation thesis. Brno university of technology, Faculty of technology based in Zlin. Zlin 